\title{
A novel, nontoxic iron chelator, super-polyphenol, effectively induces apoptosis in human cancer cell lines
}

\author{
Toshiaki Ohara ${ }^{1,2}$, Yasuko Tomono ${ }^{3}$, Xing Boyi ${ }^{1}$, Sun Yingfu ${ }^{1}$, Kazuhiro Omori ${ }^{4}$ and \\ Akihiro Matsukawa ${ }^{1}$ \\ ${ }^{1}$ Department of Pathology \& Experimental Medicine, Okayama University Graduate School of Medicine, Dentistry and \\ Pharmaceutical Sciences, Okayama, Japan \\ ${ }^{2}$ Department of Gastroenterological Surgery, Okayama University Graduate School of Medicine, Dentistry and Pharmaceutical \\ Sciences, Okayama, Japan \\ ${ }^{3}$ Shigei Medical Research Institute, Okayama, Japan \\ ${ }^{4}$ Department of Periodontics and Endodontics, Okayama University Hospital, Okayama, Japan \\ Correspondence to: Toshiaki Ohara, email: t_ohara@cc.okayama-u.ac.jp \\ Keywords: iron; chelation; chelator; apoptosis; toxicity
}

Received: April 11, $2017 \quad$ Accepted: July 29, $2018 \quad$ Published: August 28, 2018

Copyright: Ohara et al. This is an open-access article distributed under the terms of the Creative Commons Attribution License 3.0 (CC BY 3.0), which permits unrestricted use, distribution, and reproduction in any medium, provided the original author and source are credited.

\section{ABSTRACT}

Iron chelation therapy is the main treatment for iron overload disease. Iron chelators were recently reported to be useful for cancer therapy; however, they cause side effects that make them difficult to use in some cancer patients. Thus, a novel oral iron chelator, super-polyphenol (SP), was developed for cancer therapy to decrease the side effects. SP is either water soluble or insoluble, and has different isoforms according to the number of side chains. Of these isoforms, water-soluble SP6 and SP10 appear to be the best candidates, as they have the strongest chelating abilities. In this study, we focused on the usefulness and safety of SP6 and SP10 as anti-cancer drugs, and examined their anti-cancer effects and toxicity. The results showed that SP6 and SP10 inhibited cancer cell proliferation by inducing apoptosis in HCT116, HSC-2, A549, and MCF-7 cancer cells. SP10 also inhibited tumor growth in an HCT116 xenograft model. SP6 and SP10 had no acute toxicities. An intravenous injection test revealed that SP6 and SP10 had better safety profiles than the iron chelator deferoxamine. In conclusion, SP is a novel oral iron chelator with anti-cancer effects and few adverse side effects. This is the first report of SP in the literature.

\section{INTRODUCTION}

Iron is an essential element for all living organisms and plays an important role in critical cellular processes such as energy production and DNA synthesis. Although adequate iron levels are essential for human health, iron overload causes some disorders such as hemochromatosis, which is often referred to as iron overload disease [1]. In addition, iron overload is a common complication in patients receiving blood transfusion as a treatment for conditions such as aplastic anemia and myelodysplastic syndrome [2]. Moreover, iron overload causes carcinogenesis in some organs [3] by causing oxidative damage of DNA by the Fenton reaction [4]. Thus, iron depletion by an iron chelator has been explored as a possible therapeutic intervention in cancer. Some iron chelators have been shown to inhibit cancer cell proliferation, either alone or in combination with other anti-cancer drugs [5-8]. However, iron chelators can cause potentially serious side effects. For example, deferasirox (DFX), an oral iron chelator, has superior iron chelation ability, but causes digestive, liver, and kidney disorders [9]. Deferoxamine (DFO) is an intravenous iron chelator that also has toxic side effects [10]. Decreasing the side effects of iron chelators may improve cancer treatment compliance, thereby improving clinical outcomes. 
A novel iron chelator was developed by Dr. Nishida [11] for the reduction of side effects, and was named "super-polyphenol (SP)." SP is either water-soluble or insoluble. Water-soluble SP has few side effects as it is thought to avoid metabolism by cytochrome P450; drug metabolism via the cytochrome P450 system can cause drug interactions that result in drug toxicity $[12,13]$. SP has several isoforms according to the number of side chains. Of these, water-soluble SP6 and SP10 are thought to be the best candidates, as they have the strongest chelating abilities. Thus, in this study, we focused on the usefulness and safety of SP6 and SP10 as anti-cancer drugs, and examined their anti-cancer effects and toxicity.

\section{RESULTS}

\section{SP6 and SP10 chelated ferric ion in a dose- dependent manner}

SP6 was made by a condensation reaction with glucosamine, and SP10 was made by a condensation reaction with histidine (Figure 1A). We examined their basic chelating abilities using standard ferric $\left(\mathrm{Fe}^{3+}\right)$ water solution by the sulfosalicylic acid visual colorimetric method. SP6 and SP10 chelated $\mathrm{Fe}^{3+}$ in a dose-dependent manner (Figure 1B). A dose of $0.5 \mathrm{mg} / \mathrm{mL} \mathrm{SP6} \mathrm{chelated}$ more than $75 \%$ of iron, and $0.1 \mathrm{mg} / \mathrm{mL}$ SP10 chelated more than $80 \%$ of iron. These results indicated that the chelating ability of SP10 was stronger than that of SP6.

\section{SP6 and SP10 suppressed cancer cell proliferation by inducing apoptosis}

To evaluate the anti-cancer effects of SP6 and SP10, we examined the cell viability of four cancer cell lines using the XTT cell viability assay. SP6 and SP10 suppressed the proliferation of cancer cells in a dose-dependent manner (Figure 2). The $\mathrm{IC}_{50}$ value was 9.3-93.2 $\mu \mathrm{g} / \mathrm{mL}$ for SP6 and $6.2-51.4 \mu \mathrm{g} / \mathrm{mL}$ for SP10 (Table 1). HCT116 cells were most sensitive to SP6 and SP10. We used the terminal deoxynucleotidyl transferase dUTP Nick-End Labeling (TUNEL) assay to determine the mechanisms underlying their anti-proliferative effects. TUNEL staining revealed apoptotic cells in the SP6 and SP10 treatment groups (Figure 3), which was quantified by Image $\mathrm{J}$ software analysis (Supplementary Figure 2A). To confirm the apoptotic

A

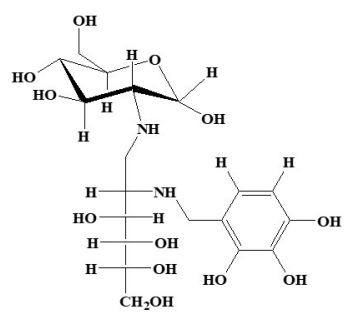

SP6

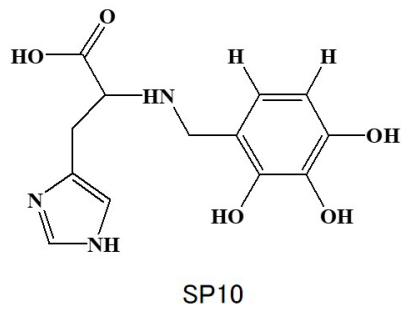

SP10

\section{B}
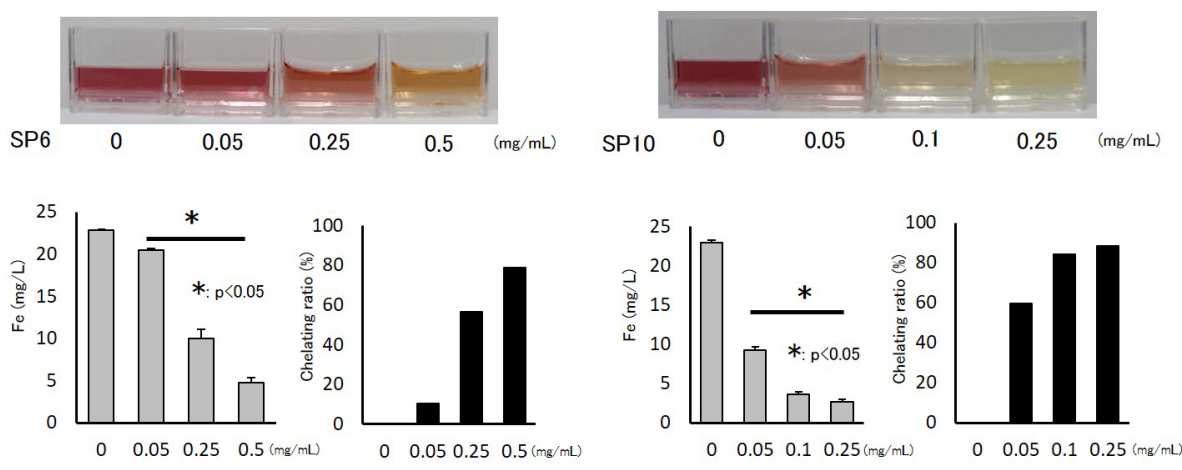

Figure 1: Structure and chelating abilities of SP6 and SP10. (A) SP was chemically synthesized from catechol and benzoic acids. SP6 was made by a condensation reaction with glucosamine, and SP10 was made by a condensation reaction with histidine. (B) The basic chelating abilities of SP6 and SP10 were examined by standard $\mathrm{Fe}^{3+}$ water solution and the sulfosalicylic acid visual colorimetric method. SP6 and SP10 were added to the standard $\mathrm{Fe}^{3+}$ solution $(22.4 \mathrm{mg} / \mathrm{L})$. The color of the liquid changed from red to yellow according to $\mathrm{Fe}^{3+}$ chelation. Data are presented as the mean \pm standard deviation (SD) $\left(n=4 ;{ }^{*} \mathrm{p}<0.05\right)$. 
effects, we performed western blot analysis (Figure 4). The expression of cleaved poly (ADP-ribose) polymerase (PARP), a DNA repair enzyme, was increased in HCT116, HSC-2, A549, and MCF-7 cells in a dose-dependent manner. The expression of cleaved caspase 3 was also increased in HCT-116, HSC-2, and A549 cells in a dosedependent manner. MCF-7 cells are caspase 3-deficient [14]. These results indicated that SP6 and SP10 suppressed the proliferation of cancer cells by inducing apoptosis.

\section{SP10 suppressed tumor growth in xenograft models by inducing apoptosis}

We expected SP10 to have stronger anti-tumor effects compared to SP6. Thus, to determine the effects of SP10 on tumor growth, we established an HCT116 tumor xenograft model using BALB/c nude mice. SP10 was orally administered at $200 \mathrm{mg} / \mathrm{kg}$ for 5 days/week. After 21 days of oral administration with vehicle control (distilled water), the tumor xenografts reached a mean volume of $358.6 \pm$ $49.9 \mathrm{~mm}^{3}$. However, SP10 significantly decreased tumor growth $\left(190.5 \pm 53.0 \mathrm{~mm}^{3}\right.$; Figure $\left.5 \mathrm{~A}\right)$. The body weight of mice did not change in both groups during the experiment (Figure 5B). To determine the mechanism underlying tumor suppression, tumors were collected and then TUNEL staining was performed, revealing apoptotic cells in the SP10 treatment group (Figure 5C). The percentage of apoptotic cells increased in the SP10 treatment group (Supplementary Figure 2B). Prussian blue staining was performed to detect ferric iron in the tumor tissue, and revealed positive blue spots that were only recognized in the stroma of the control group (Supplementary Figure 5).
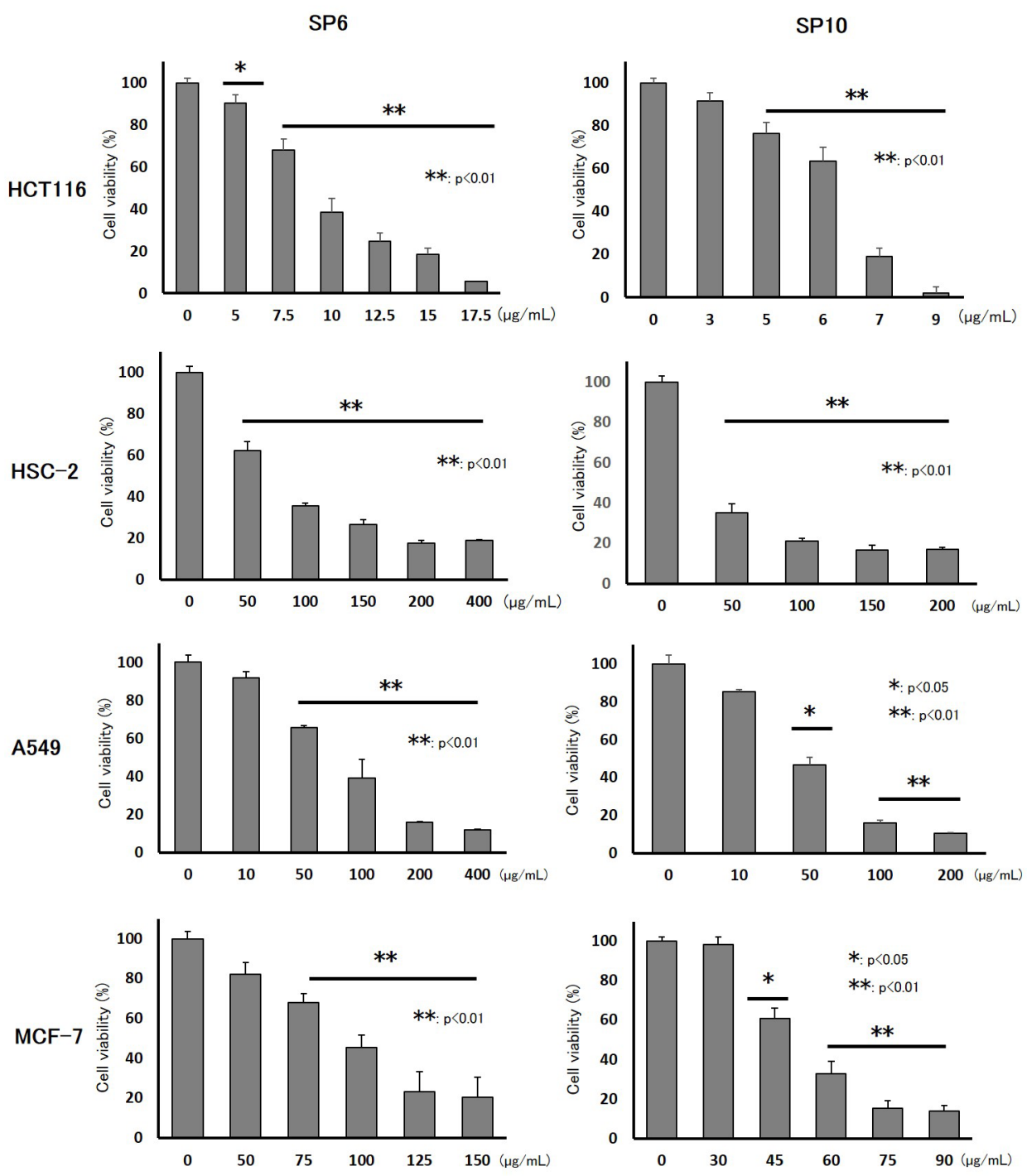

Figure 2: Inhibitory effects of SP6 and SP10 in cancer cells in vitro. Cultured HCT116, HSC-2, A549, and MCF-7 cells were treated with different concentrations of SP6 and SP10 for $72 \mathrm{~h}$, after which cell viability was evaluated using the XTT assay. Cell viability in the absence of treatment was set at $100 \%$. The results are the means of three independent experiments. Data are presented as the mean \pm standard error of the mean (SEM) $\left(n=3 ;{ }^{*} p<0.05,{ }^{* *} p<0.01\right)$. 
Table 1: $\mathrm{IC}_{50}$ of SP6 and SP10 in cancer cells

\begin{tabular}{lcc}
\hline Cell line & \multicolumn{2}{c}{$\mathbf{I C}_{\mathbf{5 0}}(\boldsymbol{\mu g} \mathbf{m} \mathbf{m L})$} \\
\cline { 2 - 3 } & SP6 & SP10 \\
\hline HCT116 & 9.3 & 6.2 \\
HSC-2 & 67.7 & 22.1 \\
A549 & 90.8 & 41.4 \\
MCF-7 & 93.2 & 51.4 \\
\hline
\end{tabular}

$\mathrm{IC}_{50}$ values $(\mu \mathrm{g} / \mathrm{mL})$ of SP6 and SP10 after a $72-\mathrm{h}$ incubation at $37^{\circ} \mathrm{C}$ using each cell line.

These results showed that SP10 suppressed tumor growth by inducing apoptosis, similar to the in vitro data.

\section{Acute oral toxicity and intravenous injection tests demonstrated the safety of SP6 and SP10}

Acute toxicity tests in rats were performed to evaluate the basic toxicity of SP6 and SP10. The agents were orally administered (600 and $1000 \mathrm{mg} / \mathrm{kg}$ ), and the body weight of the rats did not change compared to the control group during the examination (Figure 6A). No abnormal behaviors were observed through the period of examination (Supplementary Table 1). A blood test was also performed in rats treated with SP6 $(1000 \mathrm{mg} / \mathrm{kg})$ and SP10 (1000 mg/kg), and no significant abnormalities were observed (Supplementary Table 2). To evaluate any possible adverse effects to the organs, we examined the liver and kidney tissues and found no injuries in the specimens (Figure 6B). To compare the safety of SP6 and SP10 to the known iron chelator DFO, an intravenous injection test was performed with all three agents. Although all mice died immediately after intravenous administration of DFO, none died after administration of SP6 or SP10 (Table 2). These results demonstrated that SP6 and SP10 are basically safe, and as such, are more beneficial for cancer therapy than DFO.

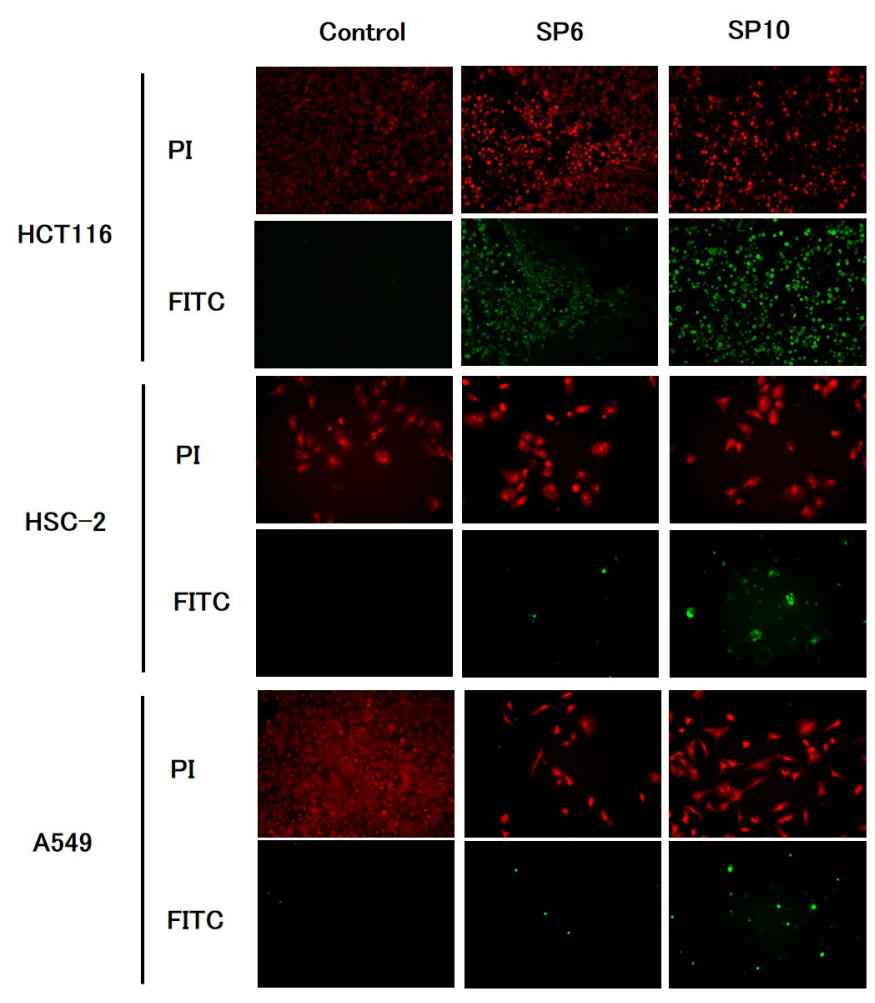

Figure 3: TUNEL staining of cancer cells in vitro. Cultured HCT116, HSC-2, A549, and MCF-7 cells were treated with different concentrations of SP6 and SP10 for $72 \mathrm{~h}$, and TUNEL staining was performed to detect apoptosis. The concentrations of SP6 used were as follows: HCT116: $10 \mu \mathrm{g} / \mathrm{mL}$, HSC-2: $100 \mu \mathrm{g} / \mathrm{mL}$, and A549: $100 \mu \mathrm{g} / \mathrm{mL}$. The concentrations of SP10 used were as follows: HCT116: 6.5 $\mu \mathrm{g} / \mathrm{mL}$, HSC-2: $50 \mu \mathrm{g} / \mathrm{mL}$, and A549: $50 \mu \mathrm{g} / \mathrm{mL}$. PI-stained nuclei were red in color. Apoptotic cells detected as FITC-positive cells were green in color. Apoptotic cells were detected in both the SP6 and SP10 treatment groups. 


\section{DISCUSSION}

This is the first report of the efficacy and safety of SP for cancer therapy. Iron chelators were originally used to treat iron overload disease caused by hemochromatosis and blood transfusion $[15,16]$. However, iron chelators have recently garnered attention as novel therapeutic agents for cancer, in part because their effectiveness was demonstrated in patients with sorafenib-refractory advanced hepatocellular carcinoma [17]. In addition, iron-rich food has been linked to an increased risk of carcinogenesis, especially breast cancer [18-21]. Thus, iron chelation therapy is expected to be a novel strategy for cancer therapy and prevention, particularly oral iron chelators compared to intravenous iron chelators due to their practicability. However, iron chelators cause potentially severe side effects, which makes them difficult to use in some cancer patients [22]. One study reported that all six hepatocellular carcinoma patients treated with DFX had side effects that led to rhabdomyolysis (increased creatinine kinase activity) or anorexia. Thus, decreasing the side effects of iron chelators may improve cancer treatment compliance, thereby improving clinical outcomes.

In this study, an acute toxicity test and blood test revealed that a high dose $(1000 \mathrm{mg} / \mathrm{kg})$ of SP6 and SP10 did not induce an abnormal appearance, cause a change in body weight, or cause organ dysfunction. A venous injection test revealed that SP6 and SP10 had a better safety profile than DFO. Although the oral iron chelator DFX was also suitable for comparison, our purchased DFX was not dissolved in distilled water and thus was technically difficult to use in

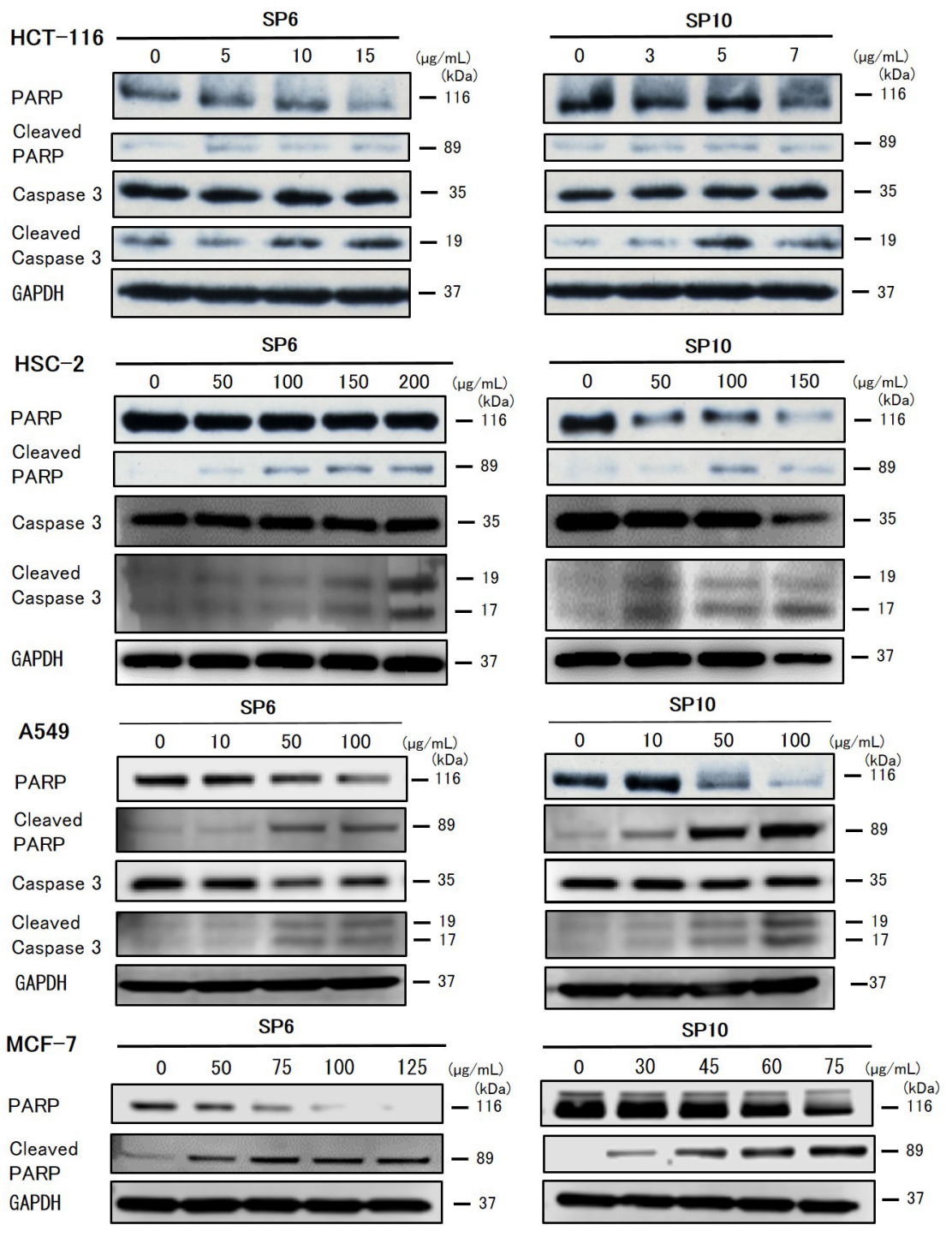

Figure 4: Western blot analysis of apoptosis in cancer cells in vitro. Cultured HSC-2, A549, and MCF-7 cells were treated with different concentrations of SP6 and SP10 for $72 \mathrm{~h}$. Then the cells were harvested and expression of the indicated proteins was analyzed. SP6 and SP10 induced expression of the apoptotic markers, cleaved caspase 3 and cleaved PARP. 
the venous injection test. Our preliminary dose escalation intravenous injection test revealed that some mice were illconditioned with administration of over $500 \mathrm{mg} / \mathrm{kg}$ SP6 and SP10 (data not shown). Together, the results of this study showed that SP6 and SP10 are basically safe, and as such, are advantageous compared to DFO. SP was developed to have decreased side effects by avoiding metabolism via cytochrome P450, as drug metabolism via the cytochrome P450 system can cause drug interactions that result in drug toxicity. Because SP6 and SP10 are water soluble, it is thought to be unaffected
A
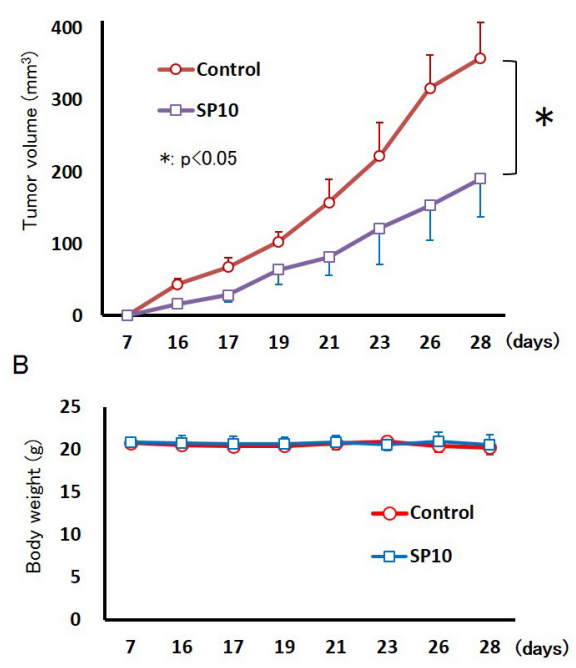

C

HE
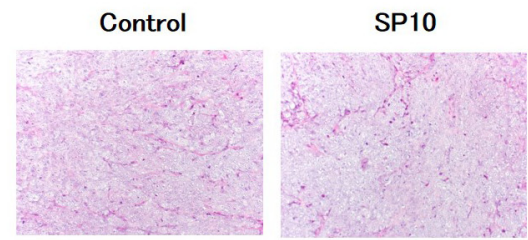

PI
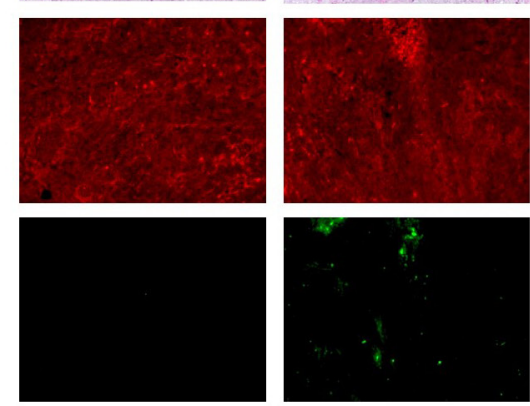

Figure 5: Anti-tumor effects of SP10 in an HCT116 tumor xenograft model. (A) HCT116 cells $\left(3 \times 10^{6}\right.$ per animal) were implanted subcutaneously into the right back flank of mice, and treatment commenced 7 days after tumor injection. SP10 (200 mg/kg orally, given 5 days/week for 21 days) effectively inhibited the growth of HCT116 allografts in vivo $\left({ }^{*}\right.$ p $\left.<0.05\right)$. (B) Body weight did not change during the experiment. (C) TUNEL staining revealed apoptotic cells in the tumor tissue of the SP10 treatment group. Hematoxylin and eosin (H\&E) staining was conducted of both the nuclei and cytoplasm. PI-stained nuclei were red in color. Apoptotic cells detected as FITC-positive cells were green color. Apoptotic cells were detected in SP10-treated tissue.

A
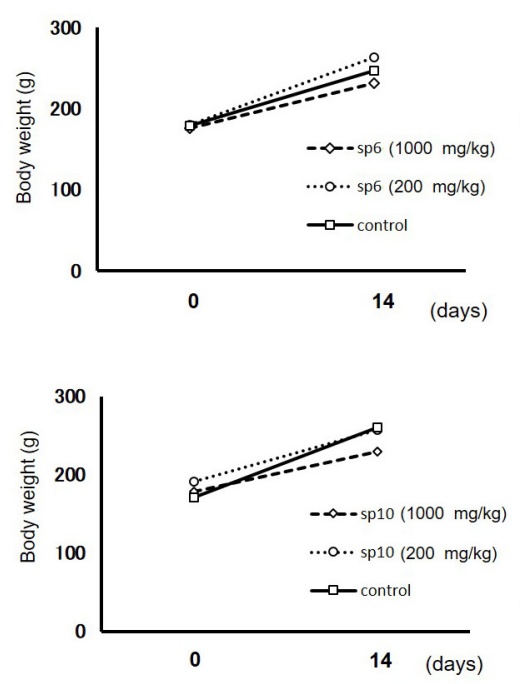

B
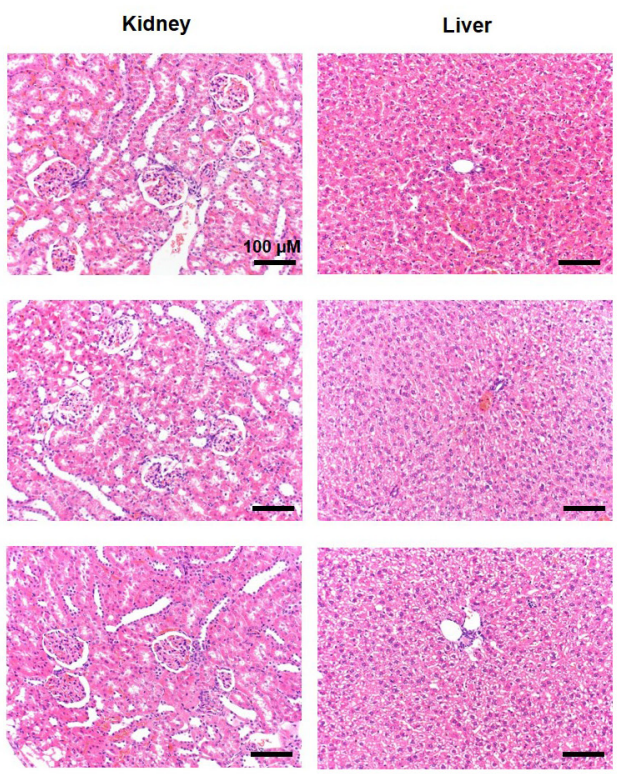

Figure 6: Evaluation of acute toxicity of SP6 and SP10 in rats. (A) SP6 and SP10 were orally administered for 14 consecutive days. Body weight was not affected by SP6 and SP10 administration. (B) Kidney and liver organs were collected after examination, and H\&E staining was performed. No disorder was detected in the SP6 and SP10 treatment groups. 


\begin{tabular}{|c|c|c|}
\hline \multicolumn{2}{|c|}{ Iron chelator } & \multirow{2}{*}{$\frac{\text { Vital result }}{\text { Dead }}$} \\
\hline DFO & 1 & \\
\hline $300 \mathrm{mg} / \mathrm{kg}$ & 2 & Dead \\
\hline & 3 & Dead \\
\hline & 4 & Dead \\
\hline \multirow{3}{*}{$\begin{array}{c}\text { SP6 } \\
300 \mathrm{mg} / \mathrm{kg}\end{array}$} & 1 & Alive \\
\hline & 2 & Alive \\
\hline & 3 & Alive \\
\hline \multirow{3}{*}{$\begin{array}{c}\mathrm{SP} 10 \\
300 \mathrm{mg} / \mathrm{kg}\end{array}$} & 1 & Alive \\
\hline & 2 & Alive \\
\hline & 3 & Alive \\
\hline
\end{tabular}

Each iron chelator was administered via the tail vein of Jcl:ICR mice. All mice injected with DFO died within 5 min, whereas those injected with SP6 or SP10 remained alive until they were sacrificed 2 weeks later.

by cytochrome P450. Although our blood and histological examinations did not show liver disease, the pharmacological mechanisms of SP are still unknown. There were fewer antiproliferative effects of SP6 and SP10 in WI-38 and NIH-3T3 fibroblasts compared to the cancer cells (Supplementary Figure 1). A limitation of our study was the lack of more comprehensive toxicity tests. Additional studies are needed to confirm the safety of SP for clinical use for cancer therapy.

Iron chelation ability was assessed by the sulfosalicylic acid visual colorimetric method, which showed that the chelation ability of SP was stronger than that of sulfosalicylic acid. Moreover, SP10 had strong chelation ability compared to SP6, which was thought to induce apoptosis in this study. The induction of apoptosis by SP6 and SP10 was similar to previous reports of other iron chelators [7, 23, 24]. Although MCF-7 cells are caspase 3-deficient, caspase 3 is known to induce apoptosis with upregulation of cleaved PARP $[14,25]$. We examined whether SP-6 and SP-10 were the trigger of apoptosis by using caspase- 3 inhibitor. Induction of cleaved PARP was inhibited by caspase- 3 inhibitor in HCS-2 cells, which indicated that SP-6 and SP10 triggered apoptosis (Supplementary Figure 2C). Induction of apoptosis was demonstrated in our in vitro and in vivo studies, which indicates that apoptosis may be the major anti-cancer mechanism of SP. The anti-tumor effects of SP6 were also confirmed in an HCT116 tumor xenograft model (Supplementary Figure $6 \mathrm{~A})$. Body weight did not change during the experiment (Supplementary Figure 6B). SP10 inhibited HCT116 tumor growth; however, the tumors did not disappear. Thus, further studies of these novel iron chelators combined with other anti-cancer agents should be performed to determine if their synergistic effects are more potent than treatment with either agent alone. We also examined the expression of ironrelated proteins and ferrous ion $\left(\mathrm{Fe}^{2+}\right)$ distribution in the cell (Supplementary Figures 3 and 4). Their expression tended to decrease, and $\mathrm{Fe}^{2+}$ distribution was condensed around the nuclei by administration of SP6 and SP10. These findings were evidence of iron chelation in the cancer cells.

In conclusion, SP is a novel oral iron chelator with anti-cancer effects via induction of apoptosis and few adverse side effects, and as such, may serve as a nontoxic iron chelator with high functionality. Iron chelators such as SP are expected to have anti-cancer effects not only by inhibiting cell proliferation via apoptosis but also by targeting cancer stem cells [26, 27].

\section{MATERIALS AND METHODS}

\section{Cell culture}

The human colon cancer cell line (HCT116) and breast cancer cell line (MCF-7) were purchased from American Type Culture Collection (Manassas, VA, USA). The human oral squamous cell carcinoma cell line (HSC2), lung cancer cell line (A549), human fibroblast cell line (WI-38) and murine fibroblast cell line (NIH-3T3) were purchased from the National Institutes of Biomedical Innovation, Health and Nutrition (JCRB, Osaka, Japan). HSC-2, A549, MCF-7, WI-38, and NIH-3T3 cells were cultured in Dulbecco's Modified Eagle's Medium (Sigma-Aldrich, St. Louis, MO, USA) and HCT116 cells were cultured in RPMI-1640 medium (Sigma) at $37^{\circ} \mathrm{C}$ in humidified air with $5 \% \mathrm{CO}_{2}$. The media were supplemented with $10 \%$ fetal calf serum (FCS) (Thermo Fisher Scientific, Waltham, MA, USA), $100 \mathrm{U} / \mathrm{mL}$ penicillin, and $100 \mu \mathrm{g} / \mathrm{mL}$ streptomycin (Sigma).

\section{Iron chelators}

SP was provided by Disease Adsorption System Technologies Co., Ltd. (Kanazawa, Japan). It was chemically 
synthesized from catechol and benzoic acids. SP6 was made by a condensation reaction with glucosamine, and SP10 was made by a condensation reaction with histidine. SP was developed to have few side effects by avoiding metabolism by cytochrome P450. DFO was purchased from Novartis Pharma (Tokyo, Japan). SP6, SP10, and DFO were dissolved in distilled water at the indicated concentrations for in vitro and in vivo experiments.

\section{Chelation ability test}

$\mathrm{Fe}^{3+}$ iron standard stock solution (Wako Pure Chemical Industries, Osaka, Japan) was used in this study. $\mathrm{Fe}^{3+}$ concentration was assessed by the sulfosalicylic acid visual colorimetric method using a kit (WAK-Fe ${ }^{3+}$, Kyoritsu chemical-check; Tokyo, Japan).

\section{Cell proliferation assay}

The XTT cell proliferation assay (Cell Proliferation Kit II; Roche, Mannheim, Germany) was used to assess cell proliferation. The cells were seeded in medium plus $10 \%$ FCS. The cells were incubated with SP6 and SP10 for $48 \mathrm{~h}$ at $37^{\circ} \mathrm{C}$ in medium plus $1 \% \mathrm{FCS}$, and then changed to medium plus 1\% FCS with SP6 and SP10 for $24 \mathrm{~h}$.

Optical densities were measured at 480 and $650 \mathrm{~nm}$. All experiments were performed in 96-well plates, and each experiment was repeated at least three times. The $\mathrm{IC}_{50}$ was calculated using Prism Windows software (version 6; GraphPad, La Jolla, CA, USA).

\section{TUNEL staining}

The induction of apoptosis was assessed by the TUNEL assay using the MK500 in situ Apoptosis Detection Kit (Takara Bio, Shiga, Japan) according to the manufacturer's protocol. Cancer cells were stained after treatment with SP6 and SP10 for $72 \mathrm{~h}$. Living cells were fixed in $4 \%$ paraformaldehyde at $4^{\circ} \mathrm{C}$ for $30 \mathrm{~min}$, and were treated with $70 \%$ ethanol to enhance permeability. Tumor tissue was also stained using the kit. The numbers of PIpositive and FITC-positive cells were calculated by Image J software (http://rsb.info.nih.gov/ij/).

\section{Ferrous ion staining}

$\mathrm{Fe}^{2+}$ distribution was assessed by FeRhonox-1 staining kit (Goryo Chemical, Sapporo, Japan). Cancer cells were stained according to the manufacturer's protocol after treatment with SP6 and SP10 for $72 \mathrm{~h}$. Nuclei were counterstained with Hoechst nuclear stain and observed using the fluorescence BZ-X700 microscope (KEYENCE, Osaka, Japan).

\section{Western blotting}

Proteins were extracted from whole cells after a 72 $\mathrm{h}$ incubation with medium and SP after the XTT assay was conducted. The concentrations of extracted protein were measured using standard protocols. Cells were lysed in cell lysis buffer (Cell Signaling Technology [CST], Danvers, MA, USA). Equal amounts of total cellular protein $(18-30 \mu \mathrm{g} /$ lane $)$ were separated by sodium dodecyl sulfate polyacrylamide gel electrophoresis and electrophoretically transferred to polyvinylidene difluoride filter membranes (Bio-Rad, Hercules, CA, USA) according to the manufacturer's protocol. The following primary antibodies were used: rabbit polyclonal anti-PARP antibody (No. 9542; CST), rabbit monoclonal anti-cleaved PARP antibody (No. 5625; CST), rabbit polyclonal anticaspase 3 antibody (No. 9662; CST), rabbit monoclonal anti-cleaved caspase 3 antibody (No. 9664; CST), and rabbit monoclonal anti-GAPDH antibody (No. 5174; CST). All primary antibodies were used according to the manufacturer's recommended dilution. All secondary antibodies (Santa Cruz Biotechnology, Dallas, TX, USA) were used at a 1:1000 dilution. The membranes were incubated with primary antibodies overnight at $4^{\circ} \mathrm{C}$, followed by incubation with secondary antibodies. ChemiLumi One L (Nacalai, Kyoto, Japan) and Immuno Star LD (Wako Pure Chemical Industries) were used to detect the peroxidase activity of the secondary antibodies. A caspase- 3 inhibitor was used to confirm the mechanism of apoptosis (235420-1MGCN; Merk, Darmstadt, Germany).

\section{Tumor allograft model}

All animal experiments were performed according to the Japanese Welfare and Management of Animals Act, and were conducted in accordance with institutional guidelines at Shigei Medical Research Institute (Okayama, Japan). All animal experiments were approved by the Ethics Review Committee for Animal Experimentation of Shigei Medical Research Institute (Nos. 1709, 1604011, and 160401-7). Female BALB/c (nu/nu) mice were purchased from CLEA Japan Inc. (Tokyo, Japan) and housed in sterile conditions. Experiments started when the mice were 8 weeks of age. HCT116 tumor cells in culture were harvested and re-suspended in a 1:1 ratio of phosphate-buffered saline and Matrigel (BD Biosciences, San Jose, CA, USA). Viable HCT116 cells $\left(3.0 \times 10^{6}\right)$ were injected into the right back flanks of the mice subcutaneously. Tumor size and body weight were measured for 21 days. SP10 (200 mg/kg) was suspended in distilled water and administered orally using a probe 5 days/week. The treatment was started 7 days after inoculation $(n=5)$. The control group received distilled water that was administered by local injection 5 days/ week. The tumor volume was calculated by the following formula: Length $\times$ Width $\times$ Height $\times 0.52$. This experiment was repeated after oral administration of $200 \mathrm{mg} / \mathrm{kg} \mathrm{SP6}$. At the end of the experiment, the animals were sacrificed and the tumors were collected for histological analysis. Paraffin sections were prepared from $10 \%$ formalin- 
fixed tumors and stained with hematoxylin and eosin and Prussian blue. Prussian blue staining was performed by incubating the fixed tissue in a mixture of $2 \%$ potassium ferrocyanide and 1\% hydrogen chloride for $30 \mathrm{~min}$.

\section{Acute oral toxicity test}

A total of nine female rats weighing 166-186 $\mathrm{g}$ were used. Jcl:SD rats were purchased from CLEA Japan Inc. An acute toxicity test was performed following OECD Test Guideline 423. SP6 and SP10 were orally administered at 200 and $1000 \mathrm{mg} / \mathrm{kg}$ body weight. Rats were observed for toxic signs for 14 days, after which biochemical analysis of the collected blood was performed. The kidney and liver were collected for histopathological examination, and pathological evaluation was performed by pathologists.

\section{Venous injection test}

A total of 10 male Jcl:ICR mice were used. DFO (300 mg/kg), SP6 (300 mg/kg), and SP10 (300 mg/kg) were administered via the tail vein. Mice were observed for survival for 14 days.

\section{Statistical analysis}

Data were compared against the respective control in each experiment using Student's $t$-test. P values less than 0.05 were considered statistically significant.

\section{Abbreviations}

SP, super-polyphenol; DFX, deferasirox; DFO, deferoxamine; XTT, 2,3-Bis-(2-Methoxy-4-Nitro-5Sulfophenyl)-2H-Tetrazolium-5-Carboxanilide; TUNEL, TdT-mediated dUTP nick end labeling; PARP, poly (ADP-ribose) polymerase; GAPDH, Glyceraldehyde-3phosphate dehydrogenase; PI, Propidium iodide; FITC, Fluorescein isothiocyanate; H\&E, Hematoxylin and Eosin.

\section{Author contributions}

T.O. designed the research study; T.O., Y.T., X.B., and S.Y. performed the experiments; T.O., Y.T., and X.B. analyzed the data; T.O., Y.T., K.O., and A.M. contributed to the discussion and writing of the manuscript; T.O. wrote the manuscript.

\section{ACKNOWLEDGMENTS}

We are grateful to Masaya Yamaguchi and Ken Nakajo for their kind assistance with the in vitro experiments, and to Shiho Komaki for helpful assistance with the in vivo experiments.

\section{CONFLICTS OF INTEREST}

The authors have no conflicts of interest to declare.

\section{FUNDING}

This work was supported by grants from Disease Adsorption System Technologies Co., Ltd. for Collaboration Research.

\section{REFERENCES}

1. Feder JN, Gnirke A, Thomas W, Tsuchihashi Z, Ruddy DA, Basava A, Dormishian F, Domingo R Jr, Ellis MC, Fullan A, Hinton LM, Jones NL, Kimmel BE, et al. A novel MHC class I-like gene is mutated in patients with hereditary haemochromatosis. Nat Genet. 1996; 13:399-408.

2. Wood JC. Cardiac iron across different transfusion-dependent diseases. Blood Rev. 2008; 22:S14-21.

3. Okada S, Hamazaki S, Toyokuni S, Midorikawa O. Induction of mesothelioma by intraperitoneal injections of ferric saccharate in male Wistar rats. Br J Cancer. 1989; 60:708-11.

4. Toyokuni S. Role of iron in carcinogenesis: cancer as a ferrotoxic disease. Cancer Sci. 2009; 100:9-16.

5. Ford SJ, Obeidy P, Lovejoy DB, Bedford M, Nichols L, Chadwick C, Tucker O, Lui GY, Kalinowski DS, Jansson PJ, Iqbal TH, Alderson D, Richardson DR, Tselepis C. Deferasirox (ICL670A) effectively inhibits oesophageal cancer growth in vitro and in vivo. Br J Pharmacol. 2013; 168:1316-28.

6. Lee JC, Chiang KC, Feng TH, Chen YJ, Chuang ST, Tsui KH, Chung LC, Juang HH. The iron chelator, Dp44mT, effectively inhibits human oral squamous cell carcinoma cell growth in vitro and in vivo. Int J Mol Sci. 2016; 17:17.

7. Urano S, Ohara T, Noma K, Katsube R, Ninomiya T, Tomono Y, Tazawa H, Kagawa S, Shirakawa Y, Kimura F, Nouso K, Matsukawa A, Yamamoto K, Fujiwara T. Iron depletion enhances the effect of sorafenib in hepatocarcinoma. Cancer Biol Ther. 2016; 17:648-56.

8. Ohara T, Noma K, Urano S, Watanabe S, Nishitani S, Tomono Y, Kimura F, Kagawa S, Shirakawa Y, Fujiwara T. A novel synergistic effect of iron depletion on antiangiogenic cancer therapy. Int J Cancer. 2013; 132:2705-2713.

9. Lee JW, Yoon SS, Shen ZX, Ganser A, Hsu HC, Habr D, Domokos G, Roubert B, Porter JB, and EPIC study investigators. Iron chelation therapy with deferasirox in patients with aplastic anemia: a subgroup analysis of 116 patients from the EPIC trial. Blood. 2010; 116:2448-54.

10. Vichinsky E, Onyekwere O, Porter J, Swerdlow P, Eckman J, Lane P, Files B, Hassell K, Kelly P, Wilson F, Bernaudin F, Forni GL, Okpala I, et al, and Deferasirox in Sickle Cell Investigators. A randomised comparison of deferasirox versus deferoxamine for the treatment of transfusional iron overload in sickle cell disease. Br J Haematol. 2007; 136:501-08. 
11. Nishida Y. The chemical mechanism of oxidative stress due to the non-transferrin-bound iron (NTBI). Adv Biosci Biotechnol. 2012; 3:1076-86.

12. Krasniqi V, Dimovski A, Domjanović IK, Bilić I, Božina N. How polymorphisms of the cytochrome P450 genes affect ibuprofen and diclofenac metabolism and toxicity. Arh Hig Rada Toksikol. 2016; 67:1-8.

13. Lynch T, Price A. The effect of cytochrome P450 metabolism on drug response, interactions, and adverse effects. Am Fam Physician. 2007; 76:391-96.

14. Jänicke RU, Sprengart ML, Wati MR, Porter AG. Caspase-3 is required for DNA fragmentation and morphological changes associated with apoptosis. J Biol Chem. 1998; 273:9357-60.

15. Cappellini MD, Bejaoui M, Agaoglu L, Canatan D, Capra M, Cohen A, Drelichman G, Economou M, Fattoum S, Kattamis A, Kilinc Y, Perrotta S, Piga A, et al. Iron chelation with deferasirox in adult and pediatric patients with thalassemia major: efficacy and safety during 5 years' follow-up. Blood. 2011; 118:884-93.

16. Vichinsky E, El-Beshlawy A, Al Zoebie A, Kamdem A, Koussa S, Chotsampancharoen T, Bruederle A, Gilotti G, Han J, Elalfy M. Long-term safety and efficacy of deferasirox in young pediatric patients with transfusional hemosiderosis: results from a 5-year observational study (ENTRUST). Pediatr Blood Cancer. 2017; 64:64.

17. Yamasaki T, Terai S, Sakaida I. Deferoxamine for advanced hepatocellular carcinoma. N Engl J Med. 2011; 365:576-78.

18. Diallo A, Deschasaux M, Partula V, Latino-Martel P, Srour B, Hercberg S, Galan P, Fassier P, Guéraud F, Pierre FH, Touvier M. Dietary iron intake and breast cancer risk: modulation by an antioxidant supplementation. Oncotarget. 2016; 7:79008-16. https://doi.org/10.18632/oncotarget.12592.

19. Ferrucci LM, Cross AJ, Graubard BI, Brinton LA, McCarty CA, Ziegler RG, Ma X, Mayne ST, Sinha R. Intake of meat, meat mutagens, and iron and the risk of breast cancer in the Prostate, Lung, Colorectal, and Ovarian Cancer Screening Trial. Br J Cancer. 2009; 101:178-84.
20. Sinha R, Park Y, Graubard BI, Leitzmann MF, Hollenbeck A, Schatzkin A, Cross AJ. Meat and meat-related compounds and risk of prostate cancer in a large prospective cohort study in the United States. Am J Epidemiol. 2009; 170:1165-77.

21. Tasevska N, Sinha R, Kipnis V, Subar AF, Leitzmann MF, Hollenbeck AR, Caporaso NE, Schatzkin A, Cross AJ. A prospective study of meat, cooking methods, meat mutagens, heme iron, and lung cancer risks. Am J Clin Nutr. 2009; 89:1884-94.

22. Saeki I, Yamamoto N, Yamasaki T, Takami T, Maeda M, Fujisawa K, Iwamoto T, Matsumoto T, Hidaka I, Ishikawa T, Uchida K, Tani K, Sakaida I. Effects of an oral iron chelator, deferasirox, on advanced hepatocellular carcinoma. World J Gastroenterol. 2016; 22:8967-77.

23. Lui GY, Obeidy P, Ford SJ, Tselepis C, Sharp DM, Jansson PJ, Kalinowski DS, Kovacevic Z, Lovejoy DB, Richardson DR. The iron chelator, deferasirox, as a novel strategy for cancer treatment: oral activity against human lung tumor xenografts and molecular mechanism of action. Mol Pharmacol. 2013; 83:179-90.

24. Tanaka T, Muto N, Ido Y, Itoh N, Tanaka K. Induction of embryonal carcinoma cell differentiation by deferoxamine, a potent therapeutic iron chelator. Biochim Biophys Acta. 1997; 1357:91-97.

25. Shim HY, Park JH, Paik HD, Nah SY, Kim DS, Han YS. Acacetin-induced apoptosis of human breast cancer MCF-7 cells involves caspase cascade, mitochondria-mediated death signaling and SAPK/JNK1/2-c-Jun activation. Mol Cells. 2007; 24:95-104.

26. Ninomiya T, Ohara T, Noma K, Katsura Y, Katsube R, Kashima H, Kato T, Tomono Y, Tazawa H, Kagawa S, Shirakawa Y, Kimura F, Chen L, et al. Iron depletion is a novel therapeutic strategy to target cancer stem cells. Oncotarget. 2017; 8:9840516. https://doi.org/10.18632/oncotarget.21846.

27. Raggi C, Gammella E, Correnti M, Buratti P, Forti E, Andersen JB, Alpini G, Glaser S, Alvaro D, Invernizzi P, Cairo G, Recalcati $\mathrm{S}$. Dysregulation of iron metabolism in cholangiocarcinoma stem-like cells. Sci Rep. 2017; 7:17667. 